\title{
Implementasi Game Sebagai Media Sosialisai Mitigasi Gunung Meletus Pada Siswa SD Kelas 4 Dengan Menggunakan Metode Finite State Machine dan Fuzzy Sugeno
}

\author{
Yastaqiim Muqorrobin, Fresy Nugroho, Suhartono
}

\begin{abstract}
Indonesia is a country that is vulnerable to disasters. Lack of educational media to recognize, prevent or save themselves from dangerous situations, as well as communication skills to report situations when they occur.

This research discusses the application of Sugeno fuzzy into mitigation games and focuses on how the response of the NPC to the player using artificial intelligence. The results show that Sugeno and FSM fuzzy successfully applied to NPC behavior in games with the percentage results on each variable having a value difference that is not far enough that indicates the number of possible values of NPC behavior that will appear.
\end{abstract}

Index Terms- Disaster Mitigation; Finite State Machine; Fuzzy Sugeno; Game; Volcano Eruption.

Abstrak - Indonesia merupakan negara yang rentan terhadap bencana. Kurangnya media edukasi untuk mengenali, mencegah, atau menyelamatkan diri dari situasi berbahaya, serta keterampilan berkomunikasi untuk melaporkan situasi apabila terjadi.

Pada penelitian ini membahas tentang penerapan fuzzy Sugeno kedalam game mitigasi dan memfokuskan bagaimana respon dari NPC kepada player menggunakan kecerdasan buatan. Hasil didapatkan bahwa fuzzy Sugeno dan FSM berhasil diterapkan pada perilaku NPC pada game dengan hasil persentase pada setiap varaibel memiliki nilai perbedaan yang tidak cukup jauh yang menunjukkan banyaknya nilai kemungkinan perilaku NPC yang akan muncul.

Kata Kunci- Finite State Machine; Fuzzy Sugeno; Game; Gunung Meletus; Mitigasi Bencana.

\section{PENDAHULUAN}

Tndonesia merupakan negara yang rentan terhadap Lencana. Salah satunya adalah gempa bumi dan gunung meletus. Dari Geologi Pusat Vulkanologi dan Mitigasi Bencana Geologi Republik Indonesia

Yastaqiim Muqorrobin Author is with the Informatic Engineering Departement of Maulana Malik Ibrahim Islamic State University , Malang (email yastaqiimmuqorrobin@gmail.com )

Fresy Nugroho, was with the Informatic Engineering Departement of Maulana Malik Ibrahim Islamic State University, Malang (email fresy@ti.uin-malang.ac.id )

Suhartono, was with the Informatic Engineering Departement of Maulana Malik Ibrahim Islamic State University , Malang (email suhartono@ti.uin-malang.ac.id ) menyatakan bahwa tahun 2014 Indonesia memiliki sebanyak 127 gunung api yang aktif. Dari 76 gunung dinyatakan rawan meletus [1]. Edukasi tentang mitigasi bencana perlu dikenalkan sejak usia dini, tidak terkecuali untuk siswa sekolah dasar. Saat ini, media edukasi untuk menumbuhkan kemandirian dan keselamatan dalam keadaan darurat bagi siswa sekolah dasar masih sangat kurang. Kurangnya media edukasi untuk mengenali, mencegah, atau menyelamatkan diri dari situasi berbahaya, serta keterampilan berkomunikasi untuk melaporkan situasi apabila terjadi[2].

Game sebagai media pendekatan diharapkan masyarakat khususnya siswa SD Kelas 4 dapat mengenali dan mengatasi berbagai ancaman dan dampak dar bencana gunung meletus dan gempa. Selain itu akan memudahkan pemerintah untuk mengatasi beberapa kendala dari sosialisasi mitigasi bencana yang dilakukan secara tradisional. Pada penelitian ini membahas tentang sosilasisasi mitigasi dan memfokuskan bagaimana respon dari NPC kepada player dengan menggunakan kecerdasan buatan (Artificial Intelligence) sebagai jenis pemograman yang dapat melakukan tindakan serta berpikir secara rasional pada saat yang bersamaan maupun tidak. Game simulasi dengan kecerdasan menggunakan Fuzzy Logic Sugeno serta Finite State Machine sebagai deskripsi yang menggambarkan tingkah laku NPC, hal ini dikarenakan FSM digunakan untuk menggambarkan dan menentukan tingkah laku terhadap perubahan kondisi yang terjadi. Penerapan Fuzzy Logic pada game berguna untuk menghubungkan bahasa mesin dengan bahasa manusia yang mengandung ketidakpastian (uncertainty), dan ketidaktepatan (imprecise).

\section{LANDASAN TEORI}

Penelitian sejenis yang pernah dilakukan yaitu pada penelitian yang membahas mengenai rancangan penerapan fuzzy logic Sugeno yang digunakan untuk mengatur tingkah laku musuh pada game [3]. Penelitian sejenis yang lain yaitu yang mengusulkan konsep pengayaan informasi untuk sistem rekomendasi tempat wisata menggunakan fuzzy berbasis crowdsourcing. Crowdsourcing digunakan untuk mendapatkan informasi terkini mengenai tempat 
konstektual dari kerumunan yang saat ini tersedia di tempat itu. Sebagian besar parameter kontekstual seperti kondisi lalu lintas, kondisi cuaca, kepadatan dabn lain-lain [4]. Penelitian sejenis yang lain dimana peneliti menumbuhkan minat belajar terhadap materi melalui game, dengan rasa senang yang muncul diharapkan player lebih mudah untuk memahami materi. Pemain diharuskan menjawab pertanyaan dari materi yang diberikan dengan cepat dan tepat yang dibatasi dengan waktu, pemain yang tercepat dan tepat menjawab soal akan mendapat nilai tertinggi [5]. Penelitian sejenis yang lain yaitu sosialisasi dengan menggunakan pendekatan baru berupa sosialisasi bencana dalam bentuk serious game. Dalam mendesain serious game sosialisasi bencana, menggunakan model teori aktivitas utnuk serious game dan tahapan sosialisasi bencana sebagaimana di isyaratkan dalam undang-undang tentang penanggulangan bencana dan diuraikan pusat vulkanologi dan mitigasi bencana geologi[6].

\section{METODE PENELITIAN}

\section{A. Rancangan Umum Game}

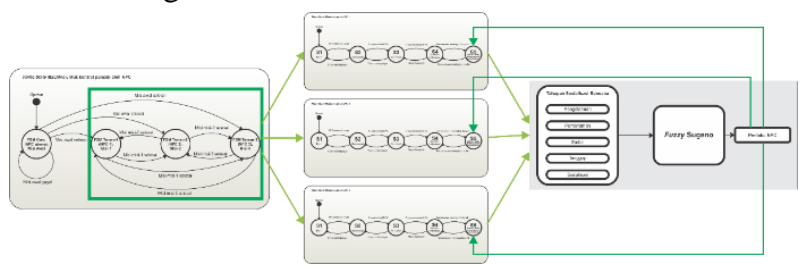

Gambar 1. Rancangan Umum Game

Penelitian yang akan dibuat akan memfokuskan pada FSM dari siswa yang mana terdapat 3 jumlah FSM yang akan diwakili oleh satu siswa dengan nama FSM siswa. Kemudian pada penerapan fuzzy Sugeno akan berpengaruh dalam FSM siswa pada state ke-5 dengan berupa 5 variabel nilai input dari sosialisasi yang dilakkan player.

\section{B. Keterangan Umum Game}

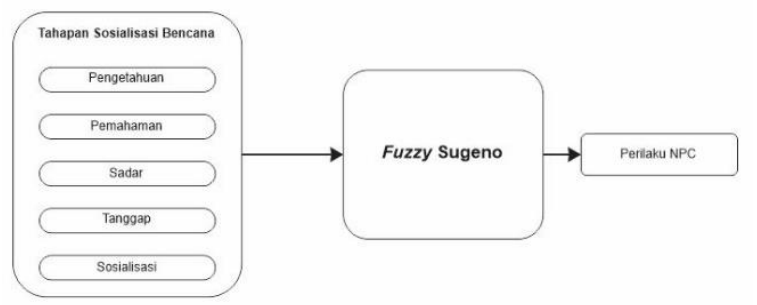

Gambar 2. Desain Periaku NPC Menggunakan Fuzzy Sugeno

Game yang dibuat adalah game pembelajaran bergenre Quiz Game dengan isi konten pengetahuan tentang mitigasi bencana gunung meletus. Nama dari game yaitu Sosialisasi Mitigasi Bencana, karena misinya adalah memberikan pengetahuan, pemahaman, kesadaran, dan tanggap mengenai bencana gunung meletus kepada NPC. Dalam game mempunyai karakter sebagai pemain yang nantinya akan digunakan oleh pemain atau penffuna, karakter siswa yang diberikan sosialisasi adalah karakter NPC dijalankan secara otomatis oleh sistem komputer. Berikut ini merupakan model game yang akan dibuat.

\section{Finite State Machine}

Dalam penelitian ini terdapat 4 bagian alur FSM yang akan berinteraksi antara pemain dengan NPC. Yang mana pada awal game, pemain diharuskan untuk berinteraksi pada NPC utama sebelum pemain berinteraksi kepada NPC lainya.

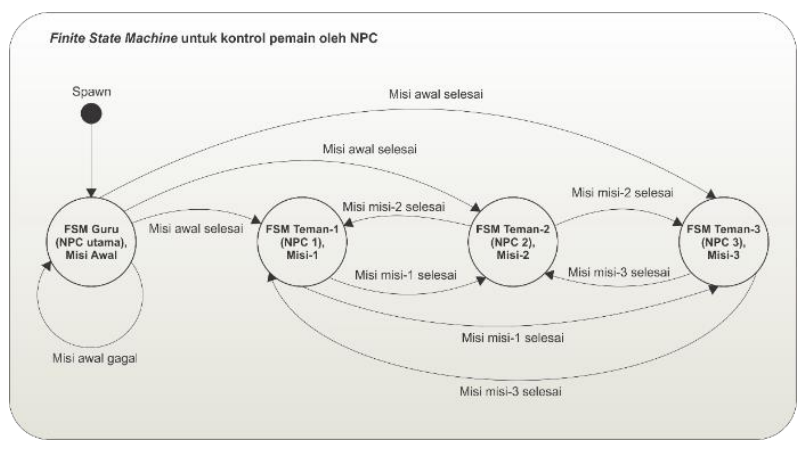

Gambar 3 FSM Kontrol Pemain Oleh NPC

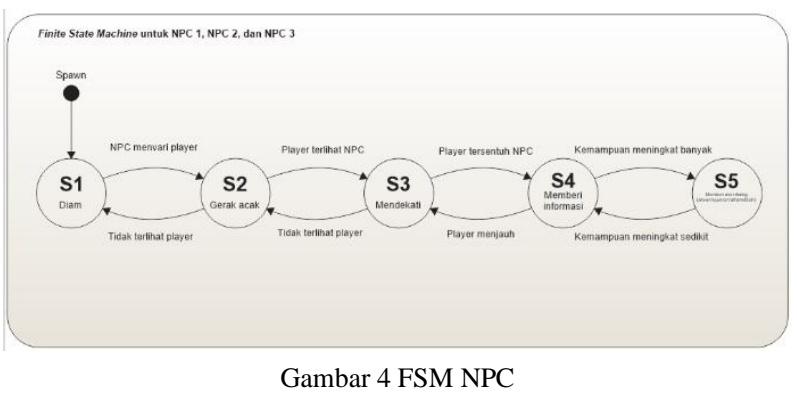

Pada FSM kontrol pemain oleh NPC terdapat 5 state yang dibuat dan pada perilaku state ke-5 akan dipengaruhi oleh inputan yang diolah menggunakan fuzzy Sugeno.

\section{Design Kemampuan NPC}

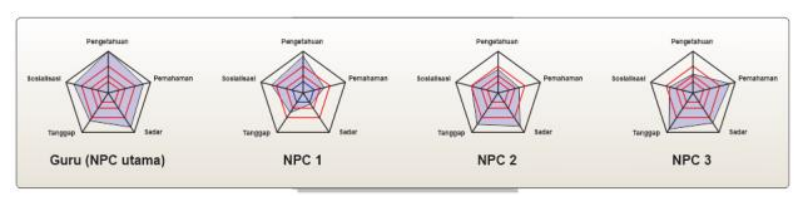

Gambar 5 Kemampuan Setiap NPC

Dalam penelitian ini terdapat 5 NPC yang memiliki kategori kemampuan yang berbeda. Dimana kategori kemampuan terdiri dari pengetahuan bencana, pemahaman bencana, sadar bencana, tanggap bencana dan sosialisasi bencana. Pengaturan besar kecilnya kemampuan awal pemain dan NPC dilakukan secara acak.

\section{HASIL DAN PEMBAHASAN}

\section{A. Nilai Linguistic dan Variabel Fuzzy}

Dalam penelitian ini terdapat 5 variabel dan 1 output yang diterapan, diantaranya:
1. Variabel pengetahuan
2. Variabel pemahaman
3. Variabel sadar
4. Variabel tanggap 
5. Variabel sosialisasi

6. Output variable keputusan:
a. Afwan
b. Syukron
c. Alhamdulillah

B. Fuzzyfikasi

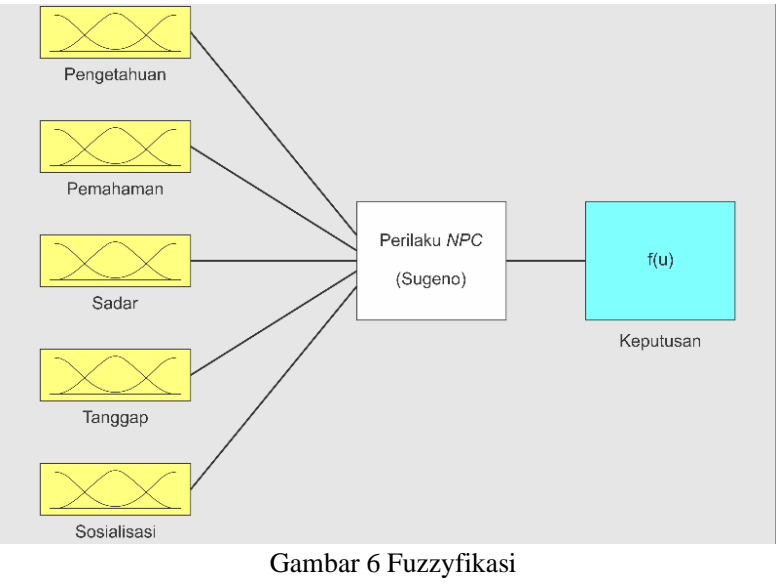

Fuzzyfikasi merupakan proses mengubah masukkan dari bentuk crisp (tegas) menjadi variabel linguistik (fuzzy) yang gambarkan berupa bentuk himpunanhimpunan fuzzy yang mana setiap variabel linguistik memiliki fungsi keanggotaanbmasing-masing.

Dan pada penelitian ini terdapat 5 variabel fuzzy yang dibuat, dengan setiap variable memiliki 3 derajat keanggotaan dengan nilai range $0-100$.

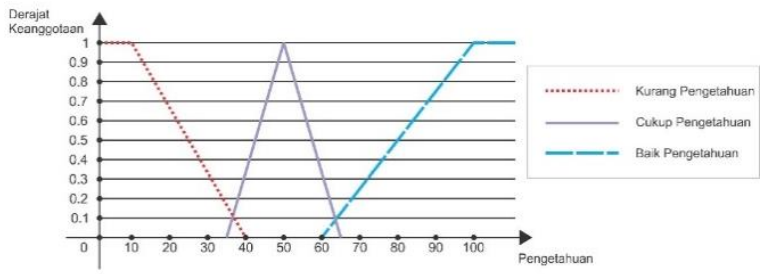

Gambar 7 Derajat Keangotaan Pengetahuan

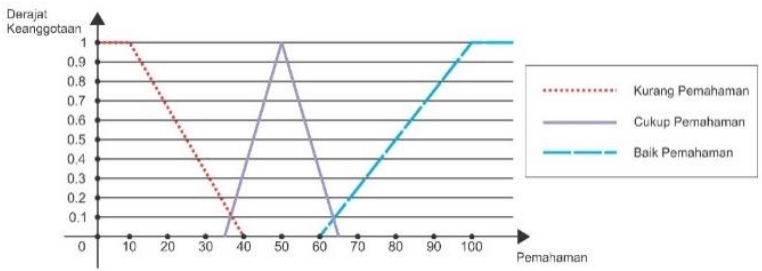

Gambar 8 Derajat Keangotaan Pemahaman

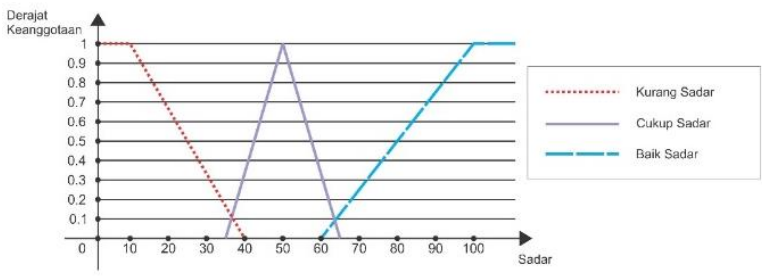

Gambar 9 Derajat Keangotaan Sadar

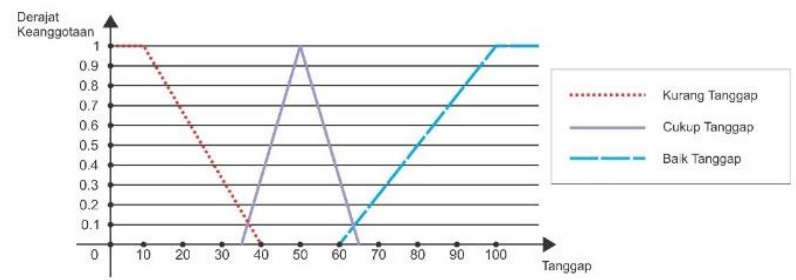

Gambar 10 Derajat Keangotaan Tanggap

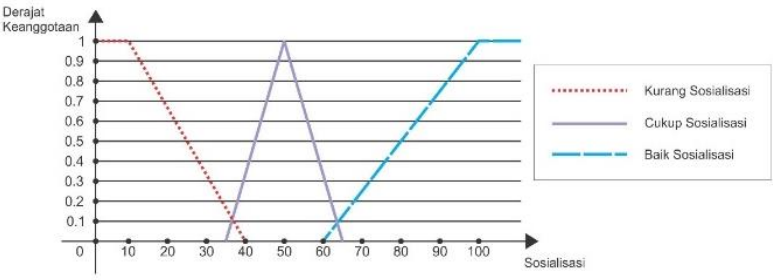

Gambar 11 Derajat Keangotaan Sosialisasi

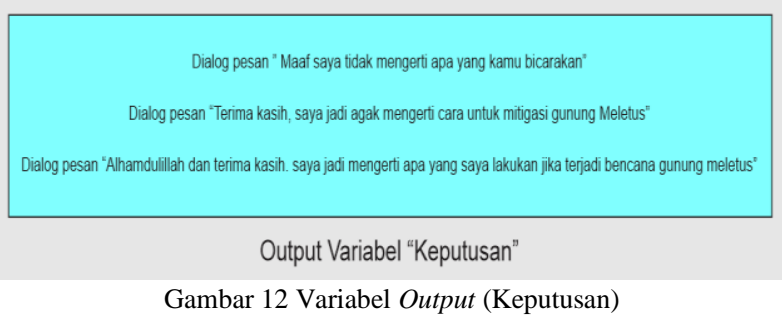

Pada Variabel output keputusanbataubaksi mempunyai tigabnilaiblinguistik dengan nilaibvariabel yang bersifatbkonstan, diantara lain: Dialog pesan "Maaf saya tidak mengerti apa yang kamu bicarakan" (disingkat: Afwan), dialog pesan "Terima kasih, saya jadi agak mengerti cara untuk mitigasi gunung Meletus" (disingkat: Syukron), dan dialog pesan "Alhamdulillah dan terima kasih. saya jadi mengerti apa yang saya lakukan jika terjadi bencana gunung meletus" (disingkat: Alhamdulillah).

\section{Rule Base}

Dari hasil fuzzyfikasi, maka didpatkan jumlah rule base maksimal sebanyak 243 aturan. Dari rule base yang telah didapatkan maka didapatkan juga 243 kemungkinan hasil atau nilai output yang berbeda yang muncul pada game.

\section{Defuzzyfikasi}

Fungsi yang digunakan yaitu implikasi MIN dan proses defuzzifikasi dilakukan menggunakan metode Rata-Rata (Average) dengan rumus:[7]

$$
\begin{aligned}
\boldsymbol{Z} & =\frac{\sum \boldsymbol{a}_{\boldsymbol{i}} \boldsymbol{z}_{\boldsymbol{i}}}{\sum \boldsymbol{a}_{\boldsymbol{i}}} \\
\boldsymbol{Z} & =\text { Keputusan } \\
\boldsymbol{a}_{\boldsymbol{i}} & =\text { Nilai derajat keanggotaan } \\
\boldsymbol{z}_{\boldsymbol{i}} & =\text { Nilai keputusan keangotaan }
\end{aligned}
$$

Melalui proses ini bertujuan untuk mendapatkan nilai minimum yang ada dalam proses fuzzyfikasi dan penetapan nilai z, maka dapat dihasilkan ai dan zi dari setiap rule.

Berdasarkan uji coba yang dilakukan pada game, 
maka akan divalidasi dengan menggunakan bantuan library fuzzy dari matlab. Dan hasil menunjukkan bahwa fuzzy pada game mempunyai nilai yang sama dengan validasi fuzzy pada matlab. Hal ini menunjukan bahwa fuzzy pada game berjalan dengan baik yang mana sesuai dengan perancanggan yang dibuat.
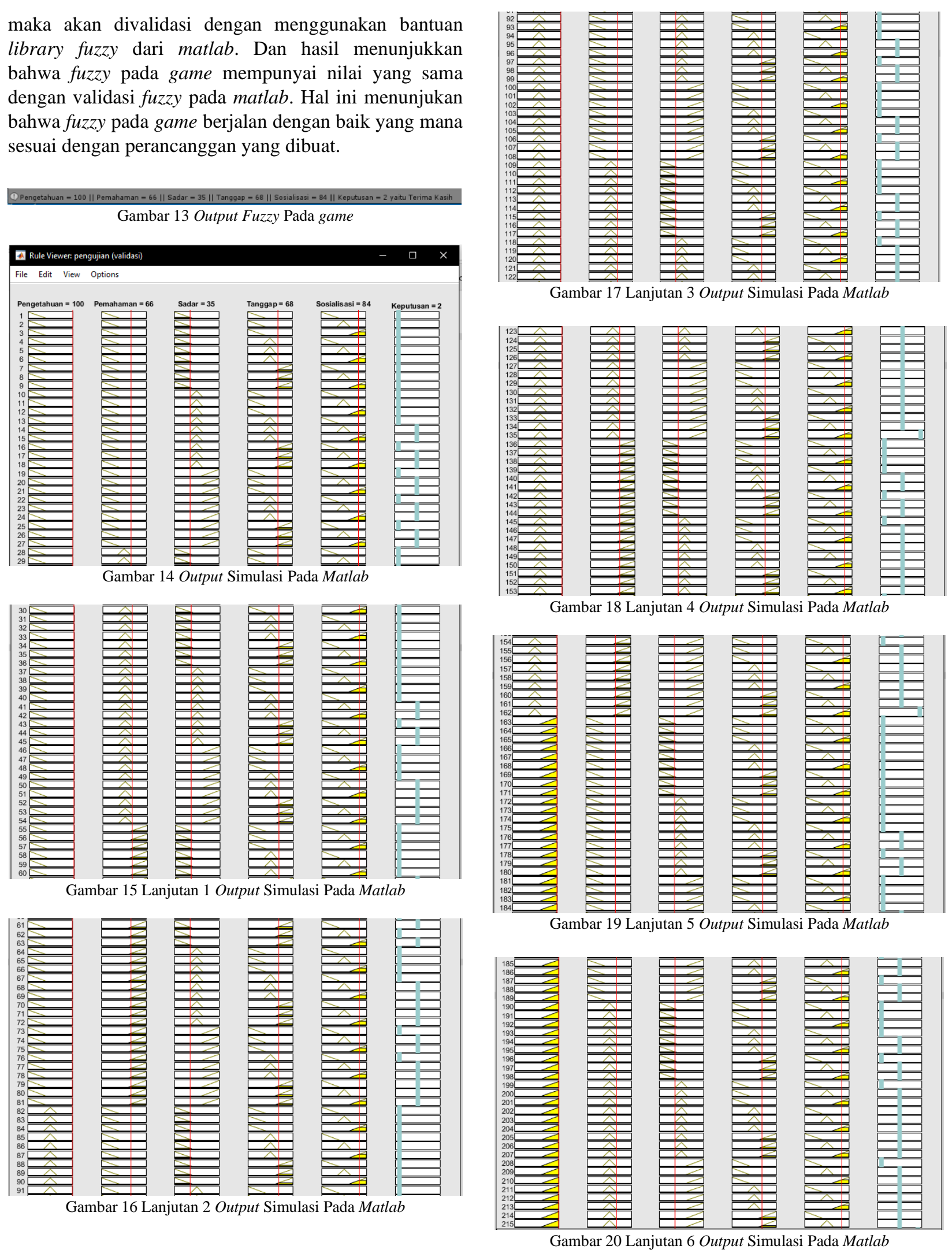


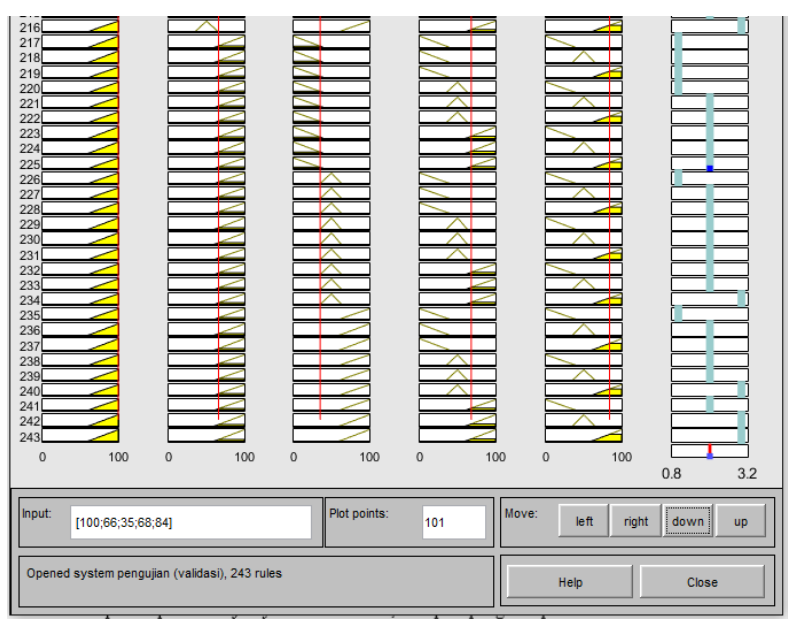

Gambar 21 Lanjutan 7 Output Simulasi Pada Matlab

Berdasarkan dari validasi yang dilakukan, maka dilakukan ujicoba sebanyak 10 kali dengan inputan yang berbeda. Dan didapatkan hasil uji coba sebagai berikut:

Tabel 1 Hasil Pengujian Logika Fuzzy Sugeno

\begin{tabular}{|c|c|c|c|c|c|c|c|}
\hline \multirow[b]{2}{*}{ No } & \multicolumn{5}{|c|}{ Input } & \multirow[b]{2}{*}{$\begin{array}{c}\text { Output } \\
\text { Game }\end{array}$} & \multirow[b]{2}{*}{$\begin{array}{c}\text { Mat } \\
\text { lab }\end{array}$} \\
\hline & $\begin{array}{l}\text { Tah } \\
\mathbf{u} \\
\end{array}$ & $\begin{array}{l}\text { Paha } \\
\text { m }\end{array}$ & $\begin{array}{l}\text { Sada } \\
\mathbf{r} \\
\end{array}$ & $\begin{array}{l}\text { Tan } \\
\text { ggap }\end{array}$ & $\begin{array}{l}\text { Sosi } \\
\text { al }\end{array}$ & & \\
\hline 1 & 21 & 80 & 46 & 34 & 58 & Afwan & 1 \\
\hline 2 & 26 & 85 & 51 & 39 & 53 & Syukron & 2 \\
\hline 3 & 31 & 24 & 87 & 44 & 58 & Syukron & 2 \\
\hline 4 & 36 & 95 & 61 & 49 & 63 & Syukron & 2 \\
\hline 5 & 100 & 45 & 56 & 26 & 70 & Syukron & 2 \\
\hline 6 & 46 & 21 & 71 & 25 & 33 & Afwan & 1 \\
\hline 7 & 51 & 100 & 76 & 64 & 78 & $\begin{array}{l}\text { Alhamdu } \\
\text { lillah }\end{array}$ & 3 \\
\hline 8 & 56 & 69 & 81 & 100 & 83 & $\begin{array}{l}\text { Alhamdu } \\
\text { lillah }\end{array}$ & 3 \\
\hline 9 & 61 & 100 & 86 & 74 & 88 & $\begin{array}{c}\text { Alhamdu } \\
\text { lillah }\end{array}$ & 3 \\
\hline 10 & 66 & 93 & 91 & 79 & 100 & $\begin{array}{c}\text { Alhamdu } \\
\text { lillah }\end{array}$ & 3 \\
\hline
\end{tabular}

Adapun berdasarkan ujicoba yang dilakukan pada siswa, maka dilakukan ujicoba sebanyak 10 kali. Dan adapun hasil yang didapatkan uji coba sebagai berikut:

\begin{tabular}{|c|c|c|c|c|c|}
\hline \multirow[t]{2}{*}{ No } & \multirow[t]{2}{*}{ Nama } & \multirow{2}{*}{$\begin{array}{c}\text { Jenis } \\
\text { Kelamin }\end{array}$} & \multicolumn{3}{|c|}{$\begin{array}{c}\text { Kriteria } \\
\text { Penelitian }\end{array}$} \\
\hline & & & $\mathbf{K M}$ & $\mathbf{M}$ & SM \\
\hline 1 & Adityama Soni Subrata & $\mathrm{L}$ & & $\sqrt{ }$ & \\
\hline 2 & Alivia Zara Ula & $\mathrm{P}$ & $\sqrt{ }$ & & \\
\hline 3 & Ana Priskah & $\mathrm{P}$ & & $\sqrt{ }$ & \\
\hline 4 & Andika Wahyu Ardiansyah & $\mathrm{L}$ & & $\sqrt{ }$ & \\
\hline 5 & Bima Setya & $\mathrm{L}$ & $\sqrt{ }$ & & \\
\hline 6 & Brian Syahrul Maghfirah & $\mathrm{L}$ & $\sqrt{ }$ & & \\
\hline 7 & Chalista Maura E. & $\mathrm{P}$ & & & $\sqrt{ }$ \\
\hline 8 & Dewi Musfiroh & $\mathrm{P}$ & & $\sqrt{ }$ & \\
\hline 9 & Dewi Rukmana Sukma & $\mathrm{P}$ & & & $\sqrt{ }$ \\
\hline 10 & Faiz Muhammad Fadhil & $\mathrm{L}$ & & $\sqrt{ }$ & \\
\hline
\end{tabular}

Keterangan:

$\mathrm{KM}=$ Kurang Menyenangkan

$\mathrm{M}=$ Menyenangkan

SM = Sangat Menyenangkan
1. $\mathrm{KM}=\frac{3}{10} \times 100=30 \%$

(2)

2. $\mathrm{M}=\frac{5}{10} \times 100=50 \%$

3. $\mathrm{SM}=\frac{2}{10} \times 100=20 \%$

Dari hasil persentase tersebut dapat diketahui bahwa nilai persentase pada $\mathrm{M}$ memiliki nilai persentase yang paling besar.

\section{KESIMPULAN}

Berdasarkan pada game yang telah dibangun dan diuji coba, didapatkan kesimpulan dimana peneliti berhasil menerapkan metode Finite State Machine dan Fuzzy Sugeno pada game sosialisasi mitigasi bencana gunung api dengan dengan menggunakan 5 variabel dengan masing-masing mempunyai 3 nilai derajat keanggotaan dengan range 0 - 100. Penelitian ini dilakukan untuk menguji Finite State Machine dan Fuzzy Sugeno yang digunakan untuk mengatur perilaku pada NPC. Dari hasil penelitian yang dilakukan, output yang keluar dalam game dicocokkan atau divalidasi dengan library fuzzy pada Matlab. Selain itu game diujikan pada siswa SD kelas 4 untuk mengetahui kelayakan game. Didapatkan data sebanyak 10 kali uji coba yang dilakukan pada fuzzy Sugeno dan uji coba 10 kali yang dilakukan pada siswa SD kelas 4. Berdasarkan pengujian data output game tersebut, didapatkan hasil pada bahwa metode finite sate machine dan fuzzy Sugeno dapat berjalan dengan baik sesuai dengan rancangan yang dibua. Berdasarkan pengujian data siswa, didpatkan bahwa persentase nilai $\mathbf{M}$ memiliki nilai persentase yang paling besar sehingga game dapat dikatakan dalam kategori menyenangkan.

\section{REFERENSI}

[1] P. B. Ajuba, "Studi Kebijakan Mitigasi Bencana Gunung Api Berbasis Kearifan Lingkungan di SDN Ngablak Srumbung Magelang," Universitas Negeri Yogyakarta, 2015.

[2] R. Kurniawan, A. Mahtarami, and R. Rakhmawati, "GEMPA: Game Edukasi sebagai Media Sosialisasi Mitigasi Bencana Gempa Bumi bagi Anak Autis," Jurnal NTETI, vol. 6, no. 2, pp. 174-183, 2017, doi: 10.22146/JNTETI.V6I2.312.

[3] K. R. Purba, Rini Nur Hasanah, and M. Azis Muslim, "Implementasi Logika Fuzzy Untuk Mengatur Perilaku Musuh dalam Game Bertipe Action-RPG," Jurnal EECCIS, vol. 7, no. 1, pp. 15-20, 2013.

[4] S. Tiwari and S. Kaushik, "Crowdsourcing Based Fuzzy Information Enrichment of Tourist Spot Recommender Systems," Journal Springer Int., vol. 7975, pp. 559-560, 2015, doi: 10.1007/978-3-642-39640-3.

[5] A. S. Huda, "Game Edukasi Cepat Tepat 
Dengan Metode Finite State Machine ( FSM ) Pada Smarthone," Universitas Islam Negeri Maulana Malik Ibrahim Malang, 2016.

[6] F. Nugroho, E. M. Yuniarno, and M. Hariadi, "Desain Serious Game Sosialisasi Bencana Berbasis Model Teori Aktifitas," Jurnal Seminar Nasional Inovasi dan Aplikasi Teknologi di Industri, 2019.

[7] M. Irfan, L. P. Ayuningtias, and J. Jumadi, "Analisa Perbandingan Logic Fuzzy Metode Tsukamoto, Sugeno, Dan Mamdani," Jurnal Teknik Informatika, vol. 10, no. 1, pp. 9-16, 2018, doi: 10.15408/jti.v10i1.6810. 